\title{
FIRST COST CALCULATION METHODS FOR ROAD FREIGHT TRANSPORT ACTIVITY
}

\author{
György Kovács \\ Institute of Logistics, University of Miskolc \\ Miskolc, Hungary \\ altkovac@uni-miskolc.hu
}

\begin{abstract}
The transport activity is one of the most expensive processes in the supply chain. Forwarding and transport companies focuses on the optimization of transportation and the reduction of transport costs.

The goal of this study is to develop a method which calculate the first (prime) cost of a given transport task more precisely than the state of the art practices. In practice the calculation of transport fee depends on the individual estimation methods of the transport managers, which could result losses for the company.

In this study the elaborated calculation method for total first cost is detailed for three types of fulfilment of transport tasks. The most common type of achievement is, when "own vehicle is used with own driver". A software was also developed for this case based on the elaborated method.

Based on the calculations of our software, the first cost can be defined quickly and precisely to realize higher profit.
\end{abstract}

Keywords: road freight transport, first cost, calculation, profit maximization, software

\section{Introduction}

In the growing market globalization, where the customer demands are changing rapidly, the enterprises have to focus on cost reduction and profitability (Kovács and Kot, 2016).

Cost reduction and improvement of efficiency are very important goals of every service providers, which gives a firm demand research in this field. The intensity of the transport activities connected to production and service is continuously increasing due to the growth of the efficiency of the economy and the bigger intercontinental supply chains.

The importance of this research study arises from the fact that $30 \%$ of the cost of the whole supply chain comes from transportation. The ratio of road transport in Europe is $78 \%$ of the total freight volume. Therefore every production and service companies put great emphasis on the optimization of transport activity (IFM, 2007).

Currently the calculation of the transport fee of a given transport task depends on the individual estimation of the transport managers. It could result in losses if the bid for the transport task is lower than the first cost of it, therefore profit would not be realized for the carrier. If the bid for the transport task is higher than the first cost the fee of the transport task would be higher than the market price, so the company would not be competitive on the market.

The goal of the research is to develop a first cost calculation method, which provides more precise result than in recent practice.

There are three alternatives for to fulfil transport tasks in practice:

1. by own vehicle and own driver,

2. by rented vehicle with own driver,

3. by rented vehicle with external contract driver (outsourcing).

The first method is the most common, when own vehicle is used with own driver, because the most important strategic aim of the companies is to maximize the utilization of resources. Second and third methods could be only relevant if the own resources (vehicle and human) are not sufficient to fulfil the clients' orders.

Since the first method is applied for most of the road freight transport volume, a software was developed for the cost calculation. Therefore this research is original and unique, because the elaborated first cost calculation method and the developed software is more precise and faster compared to the recent practices, so it can be widely used in the practical applications.

The first costs are be defined for all the three mentioned methods to fulfil a transport task. Based on the cost calculation of the three methods the carrier can decide whether it is worth completing the given transport task and which is the optimal (more profitable) method. Due to the precise calculation 
method and the software, the bid for the transport task will not be lower or higher than the market price, so risk and losses of the company can be minimized, and the profit becomes well predictable.

The elaborated calculation method and the software, helps the strategic decision making of general management, optimization of transport activity and making optimized short and long term operative plans.

\section{Reasons and Goals of the Elaboration of First Cost Calculation Method}

The reason of the elaboration of first cost calculation method is that the current common practice for the calculation of the transport fee of a transport task only based on the rough estimation of the transport managers. The transport manager has to give a quotation for the fee of transportation after receiving of a client order for a given transport task.

In this case thee price estimation is based on specific transport costs obtained from analysis of the transport data history, which could result in false fee calculation. Therefore the offered transport fee of a given transport task can be lower than the own first cost or can be much higher than that.

If the price offer for the transport task is lower than the first cost of the transport trip, profit will not be realized for the transport company. If the bid for the transport task is higher than the first cost the fee of the transport trip would be higher than the market price, so the company would not be competitive, and would not realize income.

The first cost of a given transport task has to be calculated in order to define a precise transport fee.

The goal of this research is to elaborate a precise calculation method for the total first cost of a given transport task. Then based on the elaborated theory the three alternatives to fulfil of transport tasks are evaluated:

1. by own vehicle and own driver,

2. by rented vehicle with own driver,

3. by rented vehicle with external driver (outsourcing).

At first the cost components of the total cost function are defined. Then it the first costs are defined for the three methods to fulfil a transport task. Based on the cost calculation of the three methods the carrier can make a decision whether it is worth completing the given transport task and which is the optimal (more profitable) achievement method. Based on the first cost and the expected profit the carrier can make quotation for a given transport task. The elaborated calculation methods are available for the determination of the first costs and the predictable profits of the three achievement methods of a given transport task.

The task is to elaborate a first cost calculation method, which can support the decision making of the transport managers. Based on this basic information the carrier can make a decision whether it is worth completing the given transport task and which is the optimal, most profitable achievement method.

\section{Literature Review and Methodology}

The author evaluated of the relevant literature (the most important ones included in the reference list) relating to general characteristics and cost components of road freight transport which provided the theoretical background of this study.

Many articles discuss the general logistics costs (e.g. Ross, 2015; Rushton et al., 2010) and introduction of transport cost components (e.g. Anbuudayasankar et al., 2014; Birge and Linetsky, 2007; Bokor, 2011; Gudehus and Kotzab, 2009).

The main goal of the organization of the road freight transport is to minimize the specific transport cost per unit load and to reduce the transport lead time (Caramia and Dell'Olmo, 2008; Birge and Linetsky, 2007; Ehmke, 2012).

A wide range of literature exists on route optimization and optimization of transport trips and networks (Ehmke, 2012; Birge and Linetsky, 2007; Anbuudayasankar et al., 2014; Caramia and Dell'Olmo, 2008).

There are lots of articles that discuss the general performance measurement methods and the often used KPIs (e.g. Cook and Zhu, 2005) and logistics literature rarely deals with introduction of logistics performance indicators (Schmitz and Platts, 2004; Ross, 2015). Transportation Metrics are the tools for evaluating the transportation processes. KPIs vary for different types of transportation modes (Sinha and Labi, 2007). 
In the last decade the author had several $\mathrm{R}+\mathrm{D}$ projects completed for haulage and transport companies, so has practical experience in the field of freight transportation. Currently in practice the calculation of the transport fee of a transport task depends on the individual estimation of the transport managers. The empirical experience of the author initiated the idea to elaborate a cost calculation method and technique for the three types of transport tasks solving. Before the elaboration of the calculation method the author consulted with SMEs (Small and Medium-sized Enterprises) about their requirements relating to the method. Demand for a software application has been appeared. The offered method and software was developed especially for SMEs, which enterprises cannot buy expensive ERP (Enterprise Resource Planning) systems.

The research topic is not only theoretical, but the elaborated method and software can be used very efficiently and widely in practice, because it was especially developed for SMEs for everyday use. Further advantage of developed software is that it absolutely fits to the customers' demands and very cost effective.

\section{Characteristics and Advantages of Road Freight Transport}

The ratio of road transport in Europe is $78 \%$ of the total freight volume (Fig. 1). The road transportation mode is economical mainly in local or regional scale, but it is widely used for long distances due to its other advantages.

Road transport has many advantages compared to other transportation modes:

- relatively cheap transportation mode,

- $\quad$ high density of road network,

- $\quad$ shorter transport time,

- flexible in routing and time scheduling,

- $\quad$ provides door-to-door service,

- high level of adaptation to the demands of customers,

- low risk of damage of goods during the transportation.

There is a tendency to intensify cooperation between different transportation modes (road, rail, water and air) and the volume of intermodal transportation is increased. The aim of the cooperation and coordination of transportation modes is to realize more economic and fast transport chains. The advantages and synergies between the different methods can be utilized, while at the same time the disadvantageous can be eliminated.

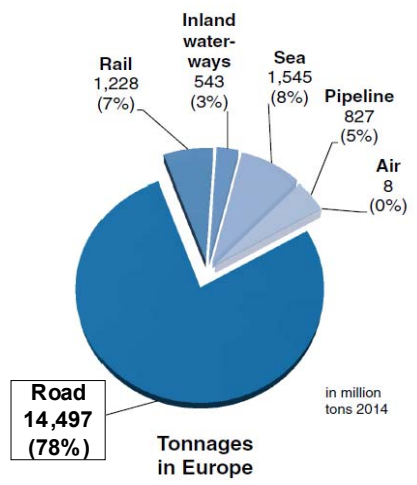

Figure 1. Ratio of transportation modes in Europe (Fraunhofer, 2015)

One of the most important aims of intermodal transportation is to reduce the volume of road transport, which can decrease the environmental pollution, traffic jams and accidents. Despite of cooperation efforts it can be forecasted that the volume of road transport will increase in the future, as a consequence road transport will be the most significant transportation mode. Therefore in the future every production companies and service providers will put great emphasis on the optimization of transportation and reduction of transport costs (Burkovskis, 2008).

\section{Network structures of transport systems}

The three basic organizational structures (Fig. 2.) of transport tasks fulfilment (connections of stations) are: line structure, ring structure and star structure (Gudehus and Kotzab, 2009). The stations can 
be the site of a company, station where the products to be transported are loaded in and station where the products to be transported are loaded out.

Depending on the locations of the stations and the freight demand, the stations can be linked in different ways to create more complex networks. Combined networks are resulted from the connection of line, ring and star networks which are: line-star-network, star-cluster-network, ring-line-network.

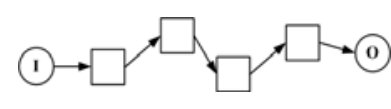

a) line structure

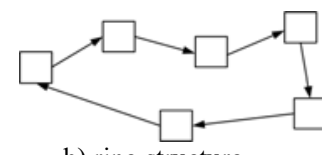

b) ring structure

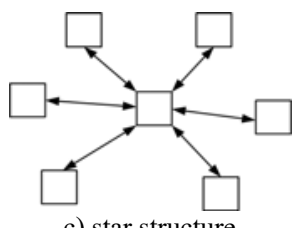

c) star structure

Figure 2. Network structures of transport systems

The most commonly used structures in road freight transport are the alternatives of ring structures and star structures. The most often applied structure in international road freight transport is the ring structure, the so called round trips.

\section{Elaboration of a First Cost Calculation Method}

1. The most common way to fulfil transport tasks at carriers and forwarding agents that have their own vehicles is to use their "own vehicle with their own driver", because the most important strategic aim of the companies is to maximize the utilization of resources. Resources include vehicles and employers. Of course it can only be realized if the company has enough resources for the achievement of a given transport task.

2. If the own resources are not sufficient to fulfil the clients' orders in case of carriers and forwarding agents that have own vehicles, it can be a relevant question if it is worth completing the given transport task with outer resources (2. by "rented vehicle with own driver" or 3. "by rented vehicle with external driver (outsourcing)") and which is the more profitable achievement method. (In practice the most common method is the first one, while the second is outsourcing.)

Since the most common achievement method is the "own vehicle with own driver", at first this method is discussed.

\subsection{First cost calculation in case of "own vehicle and own driver"}

The result of cost calculation in case of the $1^{\text {st }}$ achievement method:

Total first cost of the $j$-th transport task $\left(C_{O_{j}}^{1}\right)$ can be calculated:

$C_{O j}^{1}=C_{L j}+C_{U L j}+C_{W T j}+C_{A j}+C_{W j}+C_{M j}$,

where: $C_{L j}$ - cost of transport way with useful load; $C_{U L j}$ - cost of transport way without useful load, $C_{W T j}$ - cost of waiting time; $C_{A j}$ - total additional costs (fee of motorway usage, parking fee etc); $C_{W j}$ - labour cost of drivers; $C_{M j}$ - maintenance cost of vehicles; $j$ - identifier of the transport task.

\section{Cost of transport way with useful load}

The cost of transport way with useful load can be calculated (Kovács and Cselényi, 2006):

$C_{L j}=c_{L j} \cdot L_{L j}$

where: $L_{L j}$ - length of the way with useful load in case of $j$-th transport task $[\mathrm{km}]$,

$c_{L j}$ - specific cost of the way with useful load in case of $j$-th transport task $\left[\frac{\text { euro }}{\mathrm{km}}\right]$, 
$c_{L j}=c_{L e}\left[f_{e}+f_{e} \cdot \varepsilon_{j}^{T}+\varepsilon^{L} \cdot m_{j}\right]\left[\frac{e u r o}{k m}\right]$,

where: $c_{L e}$ - fuel price $\left[\frac{\text { euro }}{\text { liter }}\right] ; f_{e}$ - specific fuel consumption in case of empty vehicle $\left[\frac{\text { liter }}{\mathrm{km}}\right]$;

$\varepsilon^{T}$ - correction factor for fuel consumption depending on topographical conditions (flat or mountainous); $\varepsilon^{L}$ - correction factor for different loading conditions (every additional tons of useful load results in 0.5 litre extra fuel consumption) $\left[\frac{\text { liter }}{\text { ton } \cdot \mathrm{km}}\right]$;

$m_{j}$ - transported useful load [ton].

\section{Cost of transport way without useful load}

The cost of transport way without useful load can be calculated:

$C_{U L j}=c_{U L j} \cdot L_{U L j} \quad[$ euro $]$,

where: $L_{U L j}$ - length of way without load in case of the $j$-th transport task $[\mathrm{km}]$,

$c_{U L j}$ - specific cost of way without load $\left[\frac{\text { euro }}{\mathrm{km}}\right]$,

where:

$c_{U L j}=c_{L e}\left[f_{e}+f_{e} \cdot \varepsilon_{j}^{T}\right]$.

\section{Cost of waiting time}

The cost of waiting time during the transport way can be calculated:

$C_{W T j}=\left(T_{L j}+T_{W j}+T_{F j}+T_{R j}+T_{S j}\right) \cdot c_{W T j} \quad[$ euro $]$,

where:

$T_{L j}$ - time consumption of loading in and loading out [hour],

$T_{W j}$ - waiting for loading in and loading out activity [hour],

$T_{F j}$ - waiting time at the frontier station [hour],

$T_{R j}$ - waiting time due to required resting (AETR) [hour],

$T_{S j}$ - waiting time due to camion stop [hour],

$c_{W T j}$-specific waiting cost $\quad\left[\frac{\text { euro }}{\text { hour }}\right]$.

\section{Additional costs}

Total additional $\operatorname{cost}\left(C_{A j}\right)$ is the sum of the motorway fees and parking fees:

$C_{A j}=C_{A R j}+C_{A P j}[$ euro $]$,

where:

$C_{A R j}$ - fee of motorways used by vehicles; $C_{A P j}$ - parking fee.

\section{Average labour cost of drivers}

The average labour cost of drivers in case of one driver:

$C_{W j}=T_{j} \cdot c_{j}[$ euro $]$

where: $T_{j}$ - time consumption of a transport task that is the sum of time consumption of ways without useful load ( $\left.T_{U L j}\right)$ and time consumption of ways with useful load $\left(T_{L j}\right)$, and waiting times $\left(T_{W T j}\right)[$ hour $] ; c_{j}$ - average labour cost of a driver $\left[\frac{\text { euro }}{\text { hour }}\right]$. 


\section{Maintenance and operation costs of vehicles}

The maintenance cost of the company's own vehicles includes the costs that are mostly independent from the usage of vehicles, therefore this cost also appears when the vehicles are not operated (e.g.: leasing, maintenance, assurance etc).

Maintenance and operation costs of a transport task:

$$
C_{M j}=T_{j} \cdot c_{M j} \cdot \varepsilon_{M}[\text { euro }],
$$

where: $T_{j}$ - time consumption of the achievement of a transport task [day],

$\varepsilon_{M}$ - correction factor for maintenance cost of different vehicles,

$c_{M j}$ - specific maintenance cost of vehicles $\left[\frac{\text { euro }}{\text { day }}\right]$.

\subsection{First cost calculation in case of "rented vehicle and own driver"}

Rented vehicles have to be used in specific cases if:

- the own vehicles of the carrier are not sufficient to fulfil the clients' orders, but the carrier wants to take on the transport task:

- the clients' orders can be fulfilled only partially by using only their own vehicles,

- special vehicle is also required for the transport task (e.g. transport of dangerous, chemicals, frozen goods, etc.),

- the carrier's own vehicle is out of order (e.g. break down, accident, etc.),

- the client is a strategic partner, so the task has to be realized by the carrier,

- the renting cost is less than the maintenance cost of the own vehicle, etc.

The first cost calculation of a transport activity completed by rented vehicle is similar to the calculation in case of achievement by own vehicles, the difference is only that renting cost $\left(C_{R j}\right)$ has to be used instead of maintenance and operation cost components $\left(C_{M j}\right)$.

The result of cost calculation in case of the $2^{\text {nd }}$ achievement method:

The total first cost $\left(C_{O j}^{2}\right)$ in case of "rented vehicle and own driver" can be calculated as:

$C_{O j}^{2}=C_{L j}+C_{U L j}+C_{W T j}+C_{A j}+C_{W j}+C_{R j}$

The renting cost can be calculated as:

$C_{R j}=T_{j} \cdot c_{j k}$,

where: $c_{j k}$ - renting cost per time unit $\left[\frac{\text { euro }}{\text { day }}\right] ; T_{j}$ - time consumption of a transport trip [day $]$;

$k$ - identifier of the renting company.

\subsection{First cost calculation in case of "rented vehicle and contracted external driver (Outsourcing)"}

Outsourcing is a common practice applied by carriers and forwarding agents to reduce costs and increase profit by transferring the work to contracted external carriers rather than completing it internally.

The outsourcing is relevant, if:

- the carrier's own vehicles are not sufficient to fulfil the client orders in time,

- client demands can be fulfilled only by using special vehicles, which is not available at the carrier,

- the labour costs are lower at the outsourcing partner and they also have special skills and knowledge.

The result of cost calculation in case of the $3^{\text {rd }}$ achievement method is the next.

In case of outsourcing the transport activity the definition of total first cost of a transport task is easier. The first cost equals to the outsourcing fees $\left(C_{\text {Outj }}\right)$. The outsourcing fee is defined by the company that completes the outsourcing activity. 


$$
C_{O j}^{3}=C_{O u t j}
$$

\section{Profit Calculation in Case of Each Three Alternatives for Achievement of Transport Tasks}

If the transport task can be achieved by both own and rented vehicles, it has to be examined if it is worth completing a given transport task or not. If it is worth fulfilling the order, a decision has to be made upon which achievement method results in higher profit.

Of course the company will use the more profitable achievement method.

The profit can be calculated for the three alternatives as follows:

\section{Profit in case of usage of "own vehicle and own driver" $\left(P_{j}^{1}\right)$ :}

$P_{j}^{1}=R_{j}-C_{O_{j}}^{1}[$ euro $]$,

where: $R_{j}$ - revenue (selling price paid by the client for the transport service) in case of the $j$-th transport task [euro]; $C_{O_{j}}^{1}$ - total first cost of the own vehicle and the own driver in case of the $j$-th transport task [euro].

\section{Profit in case of usage of "rented vehicle with own driver" $\left(P_{j}^{2}\right)$ :}

$P_{j}^{2}=R_{j}-C_{O j}^{2}[$ euro $]$,

where: $R_{j}$ - revenue in case of the $j$-th transport task [euro]; $C_{O_{j}}^{2}$ - total first cost of the rented vehicle and the own driver in case of the $j$-th transport task [euro].

\section{Profit in case of usage of "rented vehicle and external driver (outsourcing)" $\left(P_{j}^{3}\right)$ :}

$P_{j}^{3}=R_{j}-C_{O_{j}}^{3}[$ euro $]$

where: $R_{j}$ - revenue in case of the $j$-th transport task [euro]; $C_{O_{j}}^{2}$ - outsourcing fee in case of the $j$-th transport task [euro].

The optimal achievement method will be the one that results in maximal profit for the company:

$P_{j}^{O P T}=\max \left[P_{j}^{1}, P_{j}^{2}, P_{j}^{3}\right][$ euro $]$.

Concluded:

1. Usage of own vehicle is the best solution if the profit in case of usage of "own vehicle and own driver" is higher than both in case of "rented vehicle and own driver" and "outsourcing" of the activity.

$$
P_{j}^{1}>P_{j}^{2} \text { and } P_{j}^{1}>P_{j}^{3}
$$

2. Vehicle renting is the best solution if the profit in case of usage of "rented vehicle and own driver" is higher than both in case of "own vehicle and own driver" and "outsourcing" of the activity.

$$
P_{j}^{2}>P_{j}^{1} \text { and } P_{j}^{2}>P_{j}^{3}
$$

3. Outsourcing is the best solution if the profit in case of "outsourcing" of the task is higher than both in case of "own vehicle with own driver" and "rented vehicle with own driver".

$$
P_{j}^{3}>P_{j}^{1} \text { and } P_{j}^{3}>P_{j}^{2}
$$




\section{Validation of the Elaborated Calculation Method}

The precision of the elaborated calculation method can be validated by comparing the calculated and real costs of transport tasks. The company, which defined the goals of the research, provided their historic data for this analysis. Three archived transport tasks (achieved "by own vehicle and own driver") were compared (Fig. 3.). The estimations based on their formerly used cost calculation method are also included in Table 1. The difference between real costs and calculated costs, and the difference between real costs and estimated costs were also calculated.

Table 1. Data relating to real-, calculated- and estimated costs

\begin{tabular}{|l|l|l|l|}
\hline & task 1 & task 2 & task 3 \\
\hline real cost [Eur] & 1710 & 1420 & 1190 \\
\hline calculated cost [Eur] & 1657 & 1470 & 1157 \\
\hline estimated cost [Eur] & 1915 & 1350 & 1314 \\
\hline $\begin{array}{l}\text { difference of real cost } \\
\text { and calculated cost }\end{array}$ & $-3,1 \%$ & $+3,5 \%$ & $-2,8 \%$ \\
\hline $\begin{array}{l}\text { difference of real cost } \\
\text { and estimated cost }\end{array}$ & $+12 \%$ & $-4,9 \%$ & $+10,4 \%$ \\
\hline
\end{tabular}

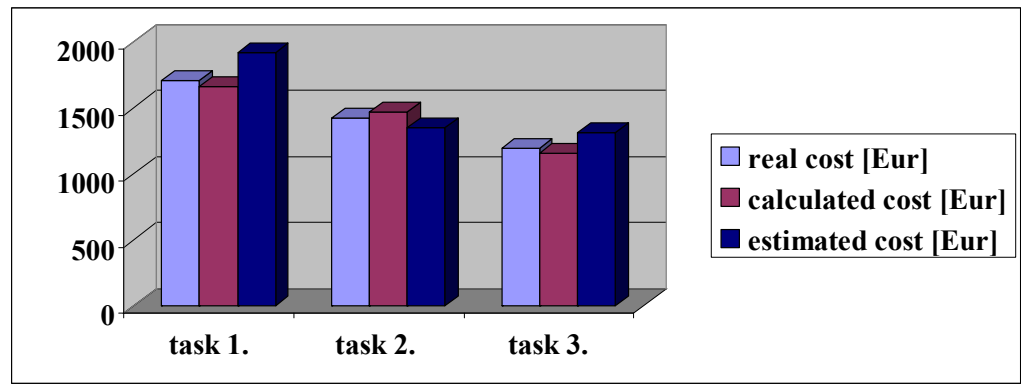

Figure 3. Comparison of real-, calculated- and estimated costs

As it emerges from Table 1 the difference between real cost and calculated cost in case of the examined three transport tasks are approximately $\pm 3,5 \%$, which is not significant in case of a long international transport trip. This result shows that the elaborated first cost calculation method is absolutely precise and reliable.

Based on the comparison between real cost and estimated cost, it can be concluded that the difference is more prominent, approximately $\pm 5-12 \%$, which is significant and represent high deviation in cost. This high difference can result in losses: if the bid for the transport task is lower than the first cost of the transport task, profit will not be realized for the carrier. If the bid for the transport task is higher than the first cost the fee of the transport task will be higher than the market price, therefore the company will not be competitive on the market, which can result in loss of market share, and strategic partners.

\section{Software Development for First Cost Calculation of Road Transport Tasks}

The developed software can be used in case of that fulfilment method, when "own vehicle is used with own driver", because it is the most common form of fulfilment of client's orders, so transport companies have great demand for it. (The theoretical background of the calculation was described in section 5.1.)

In the next part of the paper we show the most important print screens of the developed software.

The software was developed by the contribution of college Szabolcs Schmidt.

The software provides the possibility of:

1. "Data base" building and data modification,

2. "Calculation" of first cost of a road transport trips,

3. "Archive data" for listing and checking of historic calculations (Fig. 4.). 


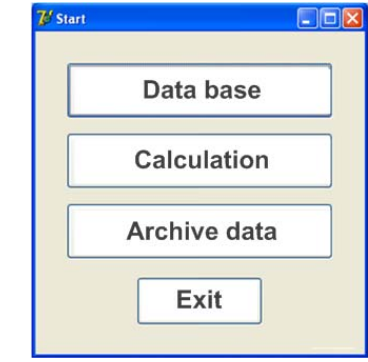

Figure 4. Main menus of the software

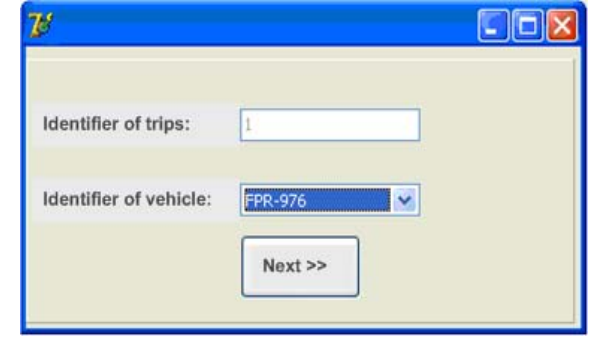

Figure 5. Screen for vehicle selection

1. In the menu "Data base" the user can define the most important parameters relating to

- transport vehicle (e.g. identifier, specific fuel consumption, specific operation-, assurance-, maintenance-, amortization costs, etc.),

- fees of motorway usage in different countries,

- actual fuel price, etc.

2. In the menu "Calculation" the user can define the most important parameters relating to the given transport task.

At first the user has to select the vehicle which will complete the transport task (Fig. 5.). The basic characteristics of the vehicle (which are in a database, e.g. specific fuel consumption in case of empty vehicle or maintenance cost) will be automatically taking into consideration during the calculation.

After it the section (transport task) and the parameters of the transport task have to be defined (Fig. 6.). The identifier of the transport task, the transport length of the task and the features of the ground (flat or mountainous) and the transported useful load have to be defined.

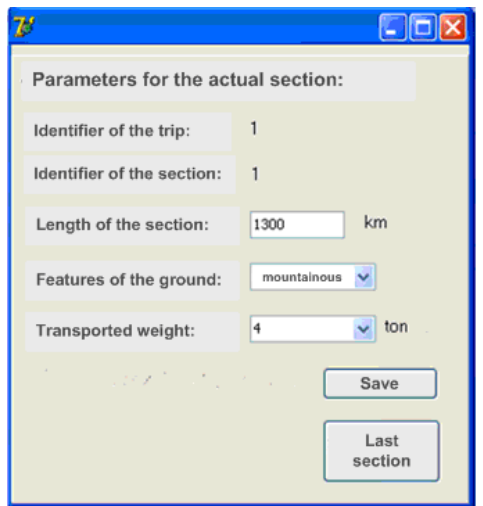

Figure 6. Screen for parameter settings of the transport task

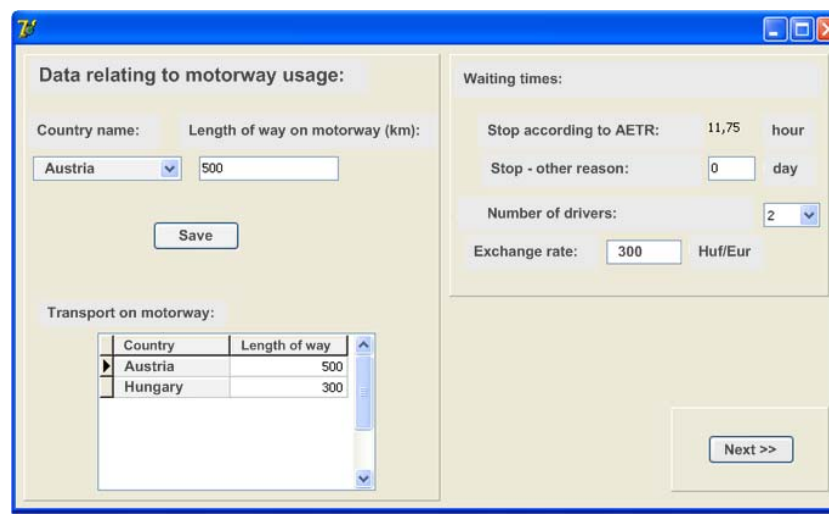

Figure 7. Screen for further parameter setting

Because of the difference of fees of motorway usage of different countries, the countries and length of motorways have to be given for all of tasks (Fig. 7.). The waiting times can be also given, because this time consumption is a waste and it has also cost. The time consumption of the total transport way is also calculated by the software, so the minimum break and rest times according to the AETR (European Agreement Concerning the Work of Crews of Vehicles Engaged in International Road Transport) rules is automatically given. The exchange rate of the Huf/Eur can be also defined, so the costs can be listed in Euro.

The number of drivers can be selected, so the wage cost is also can be taken into consideration.

After the definition of the parameters required for the calculation of the cost components (equations 2-9.) and the total first cost (equation 1.), the results of the calculation are listed in case of a given transport task (Fig. 8.).

Based on this pre-calculation of first cost of a given transport task the transport manager can give a precise transport fee offer for the clients. So the offered transport fee will not be under the own first cost or cannot be much higher than the own first cost. And the risk and waste of the company can be reduced. 


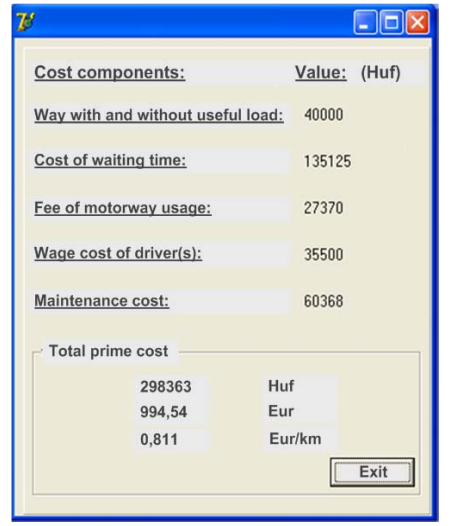

Figure 8. Screen of results of the calculation

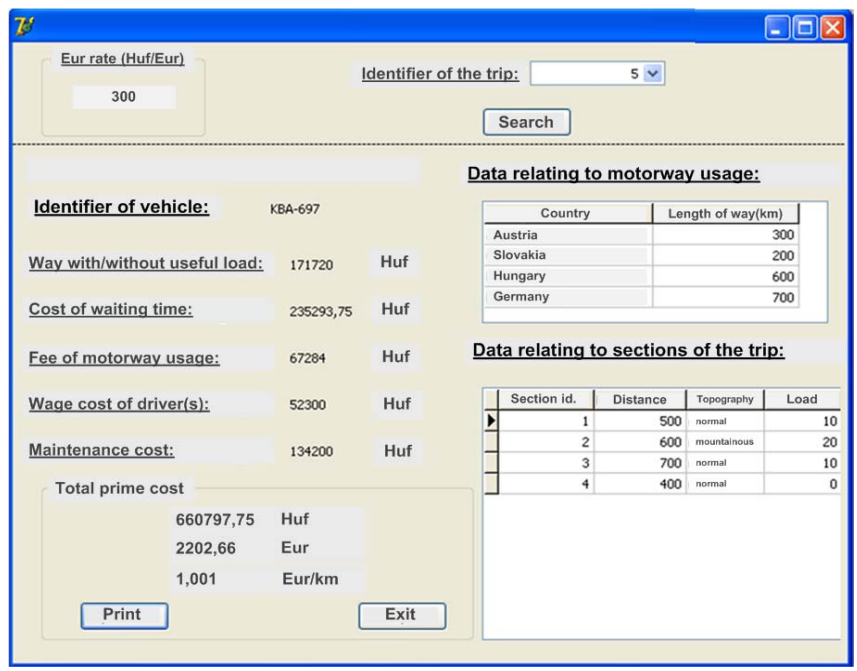

Figure 9. Screen of an archive calculation

3. In the menu "Archive data" the user can search in the earlier saved plans and calculations. Figure 9. shows an example for an archive calculation. It could be very useful if we want to compare the plans and the real data after the realization of transport tasks.

If we can measure the performance of processes we can improve it in the future.

Offered software was developed especially for SMEs, which enterprises cannot invest in expensive ERP systems. Before the software development we consulted with SMEs about their requirements relating to first cost calculation software. Based on the customer demands we elaborated the concept of the software and developed the software application.

Further advantage of our software that absolutely fit to the customer demands and very cost effective and practical oriented.

The developed software was implemented at a forwarding company. The feedback about the efficiency and applicability of our developed software is absolutely positive and other enterprises are interesting on this software.

\section{Conclusions}

Carriers and forwarding agents put great emphasis on the optimization of transportation and the reduction of transport costs, because transportation is one of the most expensive logistical processes. Therefore the optimization of road transport activities could results in significant cost reduction. This gives the importance and actuality of the present research.

Currently in practice the calculation of the transport fee of a given transport task depends on the individual estimation of the transport managers, therefore it can result in losses if the bid for a transport task is lower or higher compared to the market price.

The goal of this research was to elaborate a precise calculation method for the total first cost of a given transport task.

There are three alternatives ways to fulfil transport tasks: 1 . by own vehicle and own driver, 2 . by rented vehicle with own driver, 3 . by rented vehicle with outer driver (outsourcing).

Firstly the cost components of the total cost function were elaborated. Then it the first costs were defined for the three methods of achievement of a transport task. Based on the cost calculation of the three methods the carrier can make a decision whether it is worth completing the given transport task and which is the optimal (more profitable) achievement method. The calculated first cost and expected profit help the carrier to give a quotation for a given transport task to the client. The elaborated calculation methods are applicable for the determination of first costs and predictable profits in case of all three achievement methods of a given transport task.

The most common method to fulfil transport tasks at carriers and forwarding agents that have their own vehicles is to use their "own with their own driver", because the most important strategic aim of the companies is the maximal utilization of their resources. Since it is the most common method to fulfil the clients' orders, the transport companies have great demand for a first cost calculation method of this form. 
In order to answer this demand a software was developed for the cost calculation of this achievement method. Therefore this research is original and unique, because the elaborated first cost calculation method and the developed software is more precise and faster compared to the recent practice, so it can be widely used in case of practical applications. Due to the fastness of the software, the company will be able to provide swift respond to the clients' orders

Our software was developed especially for SMEs, which enterprises cannot invest in expansive ERP systems. Further advantage of our software is that it perfectly fits to the customer demands and very cost effective.

The developed software was successfully implemented by forwarding company; furthermore other enterprises are also interesting on this software.

In the future we plan to develop a "quasi-expert system" module for the software which can automatically make suggestions based on the evaluation of the transport activity history in order to improve freight transport activities.

\section{References}

1. Anbuudayasankar, S.P., Ganesh, K., Mohapatra, S. (2014) Models for Practical Routing Problems in Logistics. Design and Practices. Springer.

2. Birge, J.R., Linetsky, V. (2007) Handbooks in Operations Research and Management Science. North Holland.

3. Bokor, Z. (2011) Improving Transport Costing by using Operation Modelling. Transport, 26(2), 128132.

4. Burkovskis, R. (2008) Efficiency of freight forwarder's participation in the process of transportation. Transport, 23(3), 208-213.

5. Caramia, M., Dell'Olmo, P. (2008) Multi-objective management in freight logistics. Springer

6. Cook, W.D., Zhu, J. (2005) Modelling performance measurement. Springer

7. Ehmke, J.F. (2012) Integration of information and optimization models for routing in city logistics. Springer

8. Fraunhofer Institute (2015) Executive summary, Available from Internet: http://www.scs.fraunhofer.de/content/dam/scs/de/dokumente/studien/Top\%20100\%20EU\%202015\% 20Executive\%20Summary.pdf

9. IFM-Institut für Mobilitätsforschung Ed. (2007) Transport, Trade and Economic Growth - Coupled or Decoupled? Springer

10. Kovács, Gy., Cselényi, J. (2006) Utilization of historic data evaluation obtained from computer database during the organization of international transport activity. In: Proceedings of $2^{\text {nd }}$ Conference with International Participation Management of Manufacturing Systems, Presov, Slovakia, pp. 1-8.

11. Kovács, Gy., Kot, S. (2016) New logistics and production trends as the effect of global economy changes. Polish Journal of Management Studies, 14(2), 115-126.

12. Gudehus, T., Kotzab, H. (2009) Comprehensive Logistics. Springer

13. Ross, D.F. (2015) Distribution Planning and Control. Springer.

14. Rushton, A., Croucher, P., Baker, P. (2010) The handbook of logistics \& distribution management. Kogan Page Limited

15. Schmitz, J., Platts K.W. (2004) Supplier logistics performance measurement: Indications from a study in the automotive industry. Int. J. Production Economics, 89, 231-243.

16. Simchi-Levi, D., Xin, C., Bramel, J. (2014) The Logic of Logistics, Theory, Algorithms, and Applications for Logistics Management. Springer

17. Sinha, K.C., Labi S. (2007) Transportation decision making. John Wiley\&Sons Inc. 